\title{
New Opportunities in Riserless Ocean Drilling
}

\section{by Kasey White}

The JOI Alliance is operating the riserless drilling vessel contributed by the United States to the Integrated Ocean Drilling Program (IODP). Currently, the alliance, consisting of the Joint Oceanographic Institutions Inc. (JOI), and its partners, the Lamont-Doherty Earth Observatory of Columbia University (LDEO) and Texas A\&M University (TAMU), is operating the drilling vessel JOIDES Resolution, widely known for her many years of service to the Ocean Drilling Program.

During the initial stage of IODP, a new slate of drilling expeditions and a request for proposals to design and supply a new state-of-the-art riserless research vessel have generated numerous challenges and opportunities. Although a hiatus in riserless drilling was originally planned for 2005, the IODP responded to the challenge of quickly planning a schedule of expeditions for the full calendar year on topics ranging from fluids circulating beneath the seafloor to the formation of methane hydrates. Parallel efforts to obtain a new drillship are underway, with progress being made on design specifications, selection of a vessel contractor and obtaining funds from the U.S. National Science Foundation (NSF).

\section{Expeditions}

The IODP began 2005 on the JOIDES Resolution with Expeditions 304 and 305 to examine the formation of oceanic core complexes. Expedition 306 focused on the climate history of the North Atlantic Ocean. In late AprilMay, Expedition 307 obtained samples from carbonate mounds from the Porcupine Basin offshore Ireland to examine the microbiological and biogeochemical processes that affect the formation and development of these mounds. On these sites, topped by dead cold-water corals, particular emphasis was placed on the role of environmental factors and fluids as a growth trigger. Expedition 308 followed in the Gulf of Mexico and provided information on overpressured fluids beneath the seafloor and interactions of sedimentation, fluid migration, and structural deformation. Expeditions 309 and 312, Superfast Spreading Rate Crust 2 and 3 , will attempt to sample a complete section of the upper oceanic crust formed at a superfast $\left(>200 \mathrm{~mm} \mathrm{yr}^{-1}\right)$

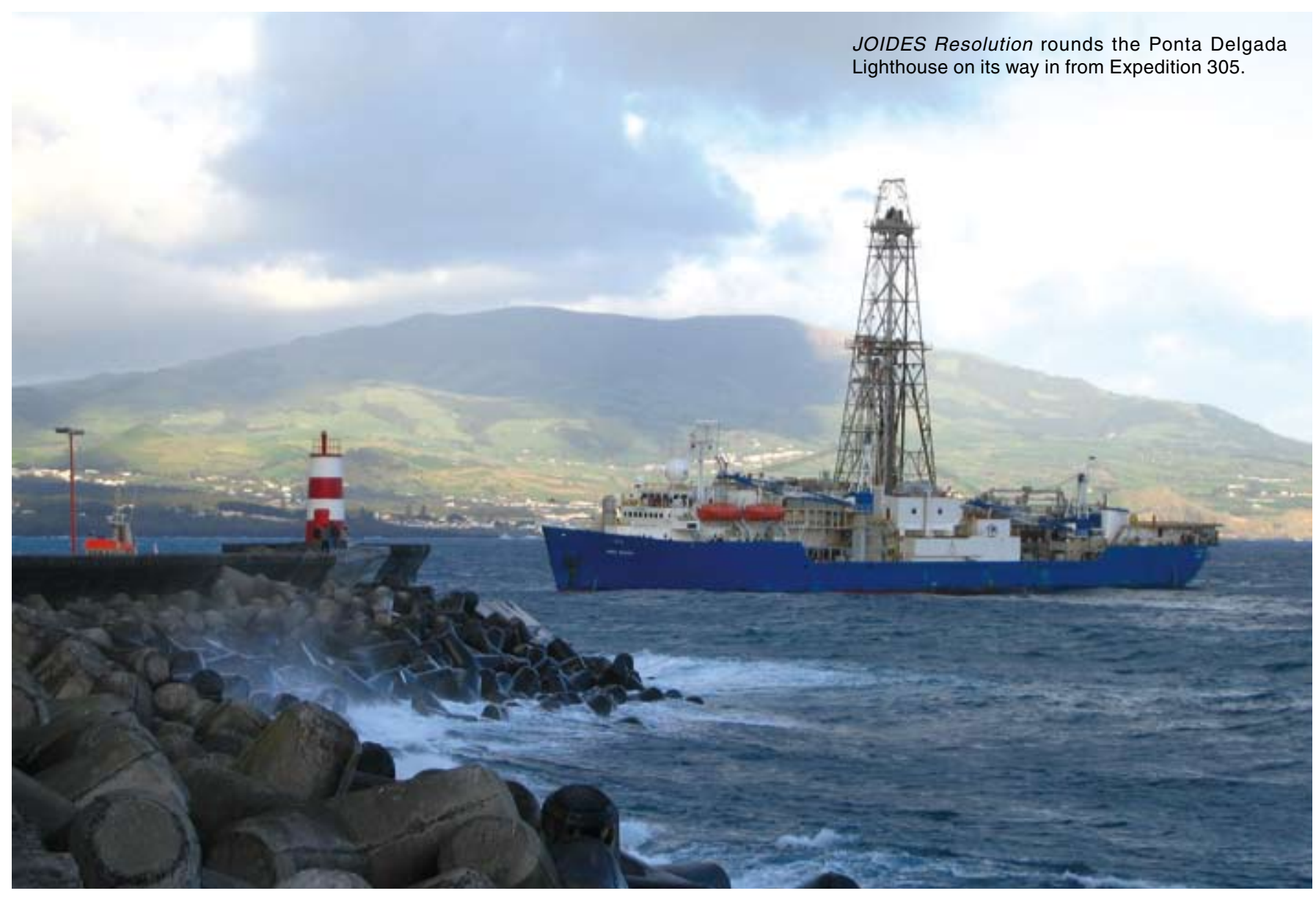




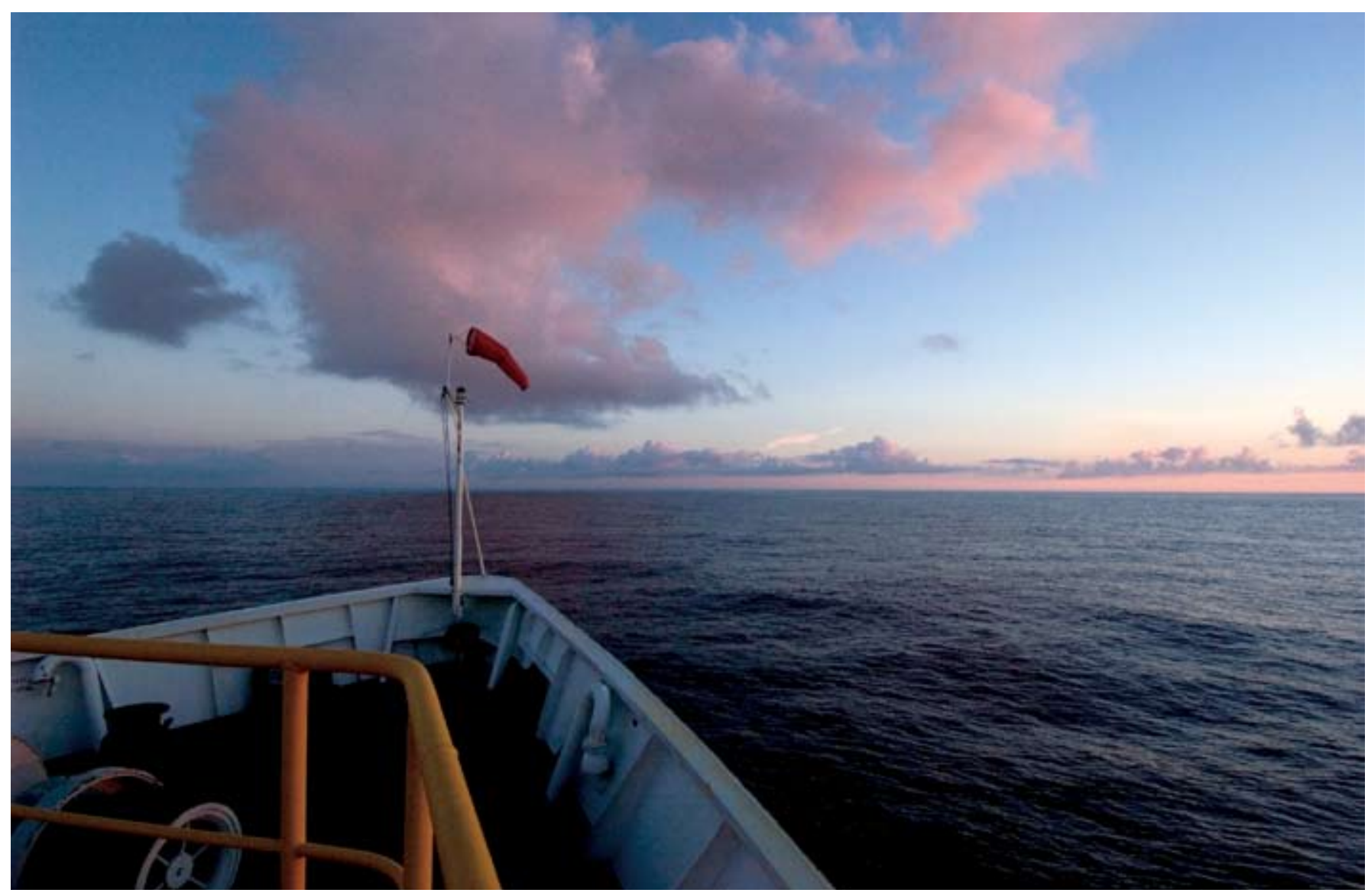

spreading ridge. The first of these expeditions took place in July-August and the second will take place October to December 2005. If successful, this will be the first sampling of a complete section of oceanic crust from extrusive pillow basalts, through sheeted dikes, and into gabbros, and it is expected to define interactions between magmatic, hydrothermal, and tectonic processes. As part of an ongoing effort to understand climate change and the possible links to the resource potential of gas hydrates, Expedition 311 in late 2005, will study the deep origin of methane on the Cascadia Margin, its upward transport, its incorporation in gas hydrates, and its subsequent loss to the seafloor. IODP plans to demobilize the JOIDES Resolution after Expedition 312 in January 2006, and awaits her replacement for resumed riserless drilling in 2007.

\section{Future Possibilities}

Plans are under way to obtain and configure a riserless drillship that will be able to meet the long-term science objectives of the IODP, relating to research of the deep biosphere and subseafloor ocean, environmental change, and solid Earth cycles. Although the JOIDES Resolution, has performed admirably for the ODP and the IODP over the past 20 years, new laboratory space and facilities and drilling capabilities are needed to conduct cutting-edge research in the 21 st century. A briefing book presenting a vision for a riserless platform as articulated by the scientific community through meetings and reports is available online at http://www.joialliance.org/MREFC/briefing_book/. The book encompasses drilling and coring capabilities, onboard scientific research capabilities, and issues of habitability.

The JOI Alliance released a request for proposals for a new drilling vessel in October 2004, and responses were due in February 2005. The review process for selecting a company to conduct the conversion and subsequent operations is ongoing, with an award expected before the end of 2005. The United States, through the NSF, is funding the conversion. In December 2004, President Bush signed into law an appropriations bill that provided the first funds (\$14.88 million) to begin the process. These funds will be used to place orders for long-lead-time drilling equipment, detailed engineering design documents, and drawings for the ship conversion package. The president has requested $\$ 57.92$ million for the coming fiscal year, with a projection to request $\$ 42.2$ million in fiscal year 2007 . Those funds will be used for converting the ship, installing the science system, and sea trials. With appropriations forthcoming, the JOI Alliance seeks to begin expeditions on the updated ship in 2007.

\section{Author}

Kasey White, formerly with Joint Oceanographic Institutions, Washington DC, U.S.A., current address: Center for Science, Technology and Congress, American Association for the Advancement of Science, 1200 New York Ave., Washington DC 20005, U.S.A., e-mail: kwhite@aas.org 